\title{
MILDIU DE LA PATATA, UNA ENFERMEDAD EN EVOLUCIÓN
}

\author{
POTATO BLIGHT, A DISEASE IN EVOLUTION
}

\author{
${ }^{1}$ Néstor Alor ; ${ }^{2}$ Raquel Marquinez; ${ }^{3}$ José Ignacio Ruiz de Galarreta
}

\begin{abstract}
RESUMEN
El Oomycete Phytophthora infestans (Mont.) de Bary, causante del mildiu de la patata ha sufrido a lo largo de su historia diferentes etapas, que han afectado a su comportamiento y agresividad. La aparición en Europa en la década de los 70 del tipo sexual A2, acabó con 130 años de estabilidad genética del patógeno. La recombinación genética favoreció la aparición de nuevas cepas del patógeno, más adaptadas, capaces de vencer resistencias y tratamientos. El presente trabajo de investigación tiene por finalidad dar a conocer la metodologia de prospección, aislamiento, identificación tanto a nivel fenotípico como molecular, ymantenimiento del patógeno $P$. infestans.
\end{abstract}

Palabras Clave: CAPS, caracterización fenotipica, caracterización genética, marcadores moleculares, tipo de apareamiento.

\section{ABSTRACT}

The Oomycete Phytophthora infestans (Mont.) de Bary, potato blight causing, has undergone different stages throughout its history, affecting its behaviour and aggressiveness. In Europe, during 70s, showed up the A2 mating type, ending with 130 years of pathogen's genetic stability. The genetic recombination favored the birth of new strains, more adapted, able to overcome resistance and the treatments against the pathogens. The aim of this research is to transfer the methodology of prospecting, isolation, phenotyping, genotyping, and maintenance of P. infestans pathogen.

Key words: CAPS, phenotypic characterization, genetic characterization, molecular markers, mating type

\section{I.INTRODUCCIÓN}

\section{El Patógeno}

Cuando el organismo causal de la enfermedad se identificó, le dieron el nombre de Phytophthora infestans (Mont.) de Bary, que significa destructor de plantas. El hongo crece en el tejido de la planta (hojas, tallos o tubérculos) formando hifas a modo de ramas en las que se producen los esporangios (Figura $\mathrm{N}^{\circ} 01$ ). Estos tienen forma de limones que se desprenden, $\mathrm{y}$ a través del viento $\mathrm{y}$ gotas de agua son transportados para colonizar otras plantas. Cuando los esporangios encuentran tejido sano, germinan y comienzan un nuevo ataque. Además de la patata, también ataca al tomate (Solanum byopersicum L.).(ver figuras $\mathrm{N}^{\circ} 01$ y 02 )

\section{Ciclo de la enfermedad}

Debido a la forma de multiplicación de la patata a partir de tubérculos y no de semilla botánica, son los propios tubérculos los que mantienen la enfermedad de un año para el siguiente. Estos tubérculos pueden ser patatas que quedan de un año para otro en el campo, los tubérculos que se tiran en vertederos o la propia semilla. Después de que la planta nace, los brotes son invadidos por el patógeno que esporula siempre que las condiciones sean favorables, produciéndose inóculo primario que se disemina hacia nuevas plantas. Con la aparición de oosporas (Figura $\mathrm{N}^{\circ} 02$ ), estas son capaces de mantenerse directamente en la tierra durante el invierno. Cuando las condiciones son favorables, germinan e infectan las hojas bajas del cultivo.

Siempre que las condiciones son favorables, el patógeno produce nuevas esporas que se vuelven a diseminar atacando tejido sano. Cuando la patata tuberiza, la lluvia o el riego arrastran los esporangios a través de la tierra. Si los esporangios llegan al tubérculo, este se contamina y perpetúa la enfermedad. La contaminación de tubérculos también puede ocurrir en el momento de la cosecha si los tubérculos entran en contacto con las ramas contaminadas. Por ello, es altamente recomendable quemar la planta o esperar a que esté completamente seca antes de proceder a cosechar los tubérculos.

Desde su llegada a Europa, las poblaciones del tizón tardio se mantuvieron muy estables, debido a que su forma de reproducción era exclusivamente asexual. Solo 


\section{Ciencia \& Desarrollo}

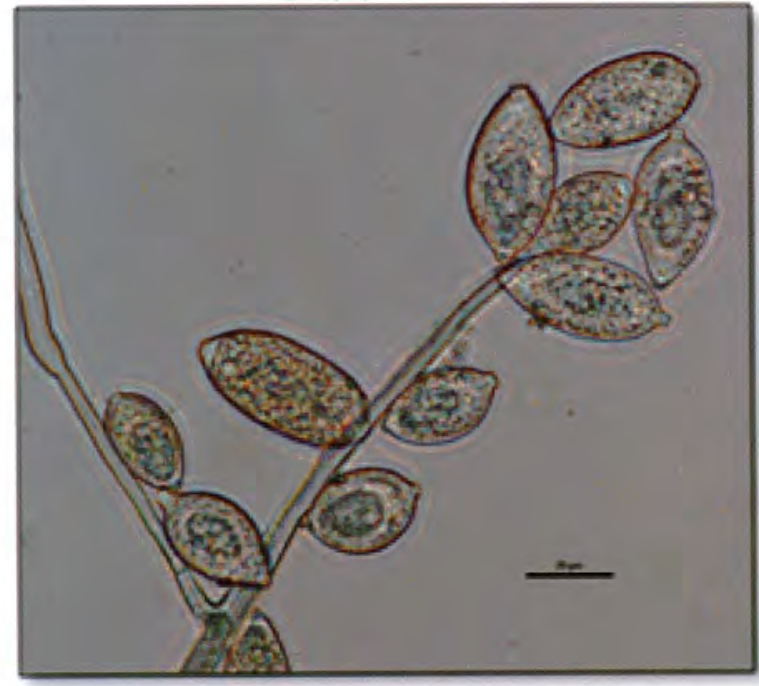

Figura $\mathbf{N}^{\circ} 01$. Esporangios de Pbytophthora infestans

había un tipo sexual en Europa, el tipo $A 1$. El otro tipo sexual, el $A 2$, estaba presente sólo en México. Desde los años 70 se ha confirmado la presencia del $A 2$ en Europa y hay evidencias de que este patógeno es capaz de reproducirse sexualmente dando lugar a oosporas. Las oosporas son estructuras más resistentes y con recombinación genética que favorece la aparición de aislados más adaptados, capaces de superar resistencias varietales, no responder a tratamientos o sobrevivir a condiciones extremas.

Se están produciendo cambios rápidos e importantes en la población del patógeno, lo que obliga a una monitorización continua de dichas poblaciones. A partir de 2004, la cepa denominada Blue 13 se ha impuesto en varios países desplazando a otras poblaciones menos agresivas. Esta cepa es resistente al metalaxyl y ha hecho necesario adaptar las estrategias de lucha para hacer frente a la enfermedad. La aparición reciente, en 2009, de la cepa Green 33 parece tener menos sensibilidad al fluazinam, haciendo necesaria una nueva adaptación de las estrategias

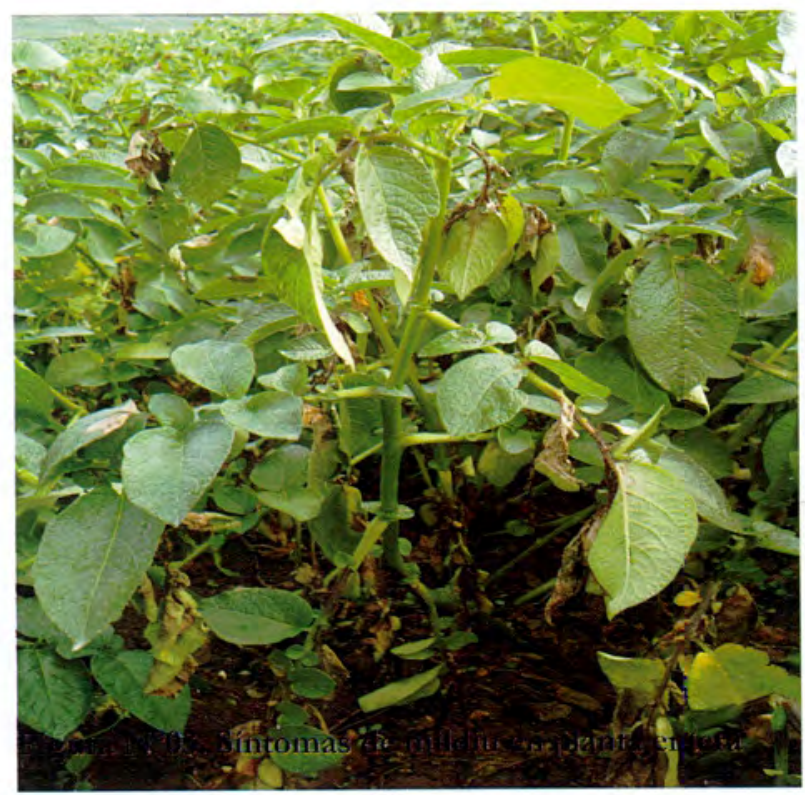

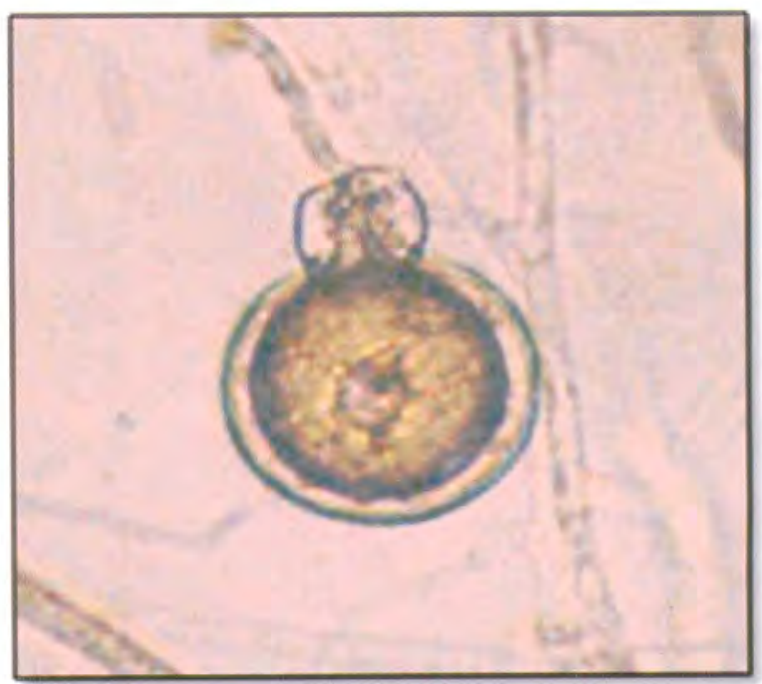

Figura $\mathrm{N}^{\circ} 02$. Oosporaprocedente de cruzamiento $A 1 \mathrm{x} A 2$

de lucha.

\section{Prospección de las muestras}

$\mathrm{El}$ aislamiento e identificación del mildiu en zonas productoras de patata, parte de la identificación de los síntomas característicos de esta enfermedad tal y como se presentan en las figuras $\mathrm{N}^{\circ} 03$ y 04 . Estos se manifiestan inicialmente en la parte aérea de la planta, en hojas inferiores, normalmente en las puntas y los bordes de los foliolos, donde una aureola verde clara o amarilla suele separar el tejido muerto del sano. Posteriormente, las lesiones progresan hacia el resto de la superficie del foliolo y pueden visualizarse en forma de manchas de color verde oscuro, pardas o negras. En el envés de las hojas se forman unas vellosidades blanquecinas que corresponden a las estructuras del patógeno. Tras la recolección de las muestras de hoja infectadas, estas se depositan en bolsas de papel o plásticas con papel absorbente humedecido, identificándola con la fecha de recolección, variedad de patata y lugar de procedencia.

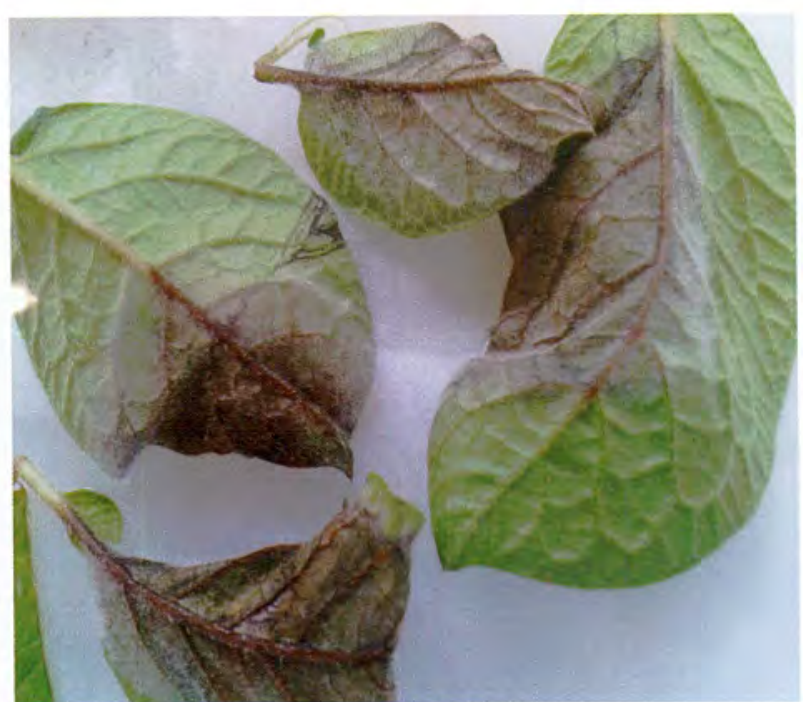

Figura $\mathrm{N}^{\circ} 04$. Síntomas de mildiu en foliolos 


\section{CONTENIDO TEMÁTICO}

\section{Aislamiento y mantenimiento del patógeno}

Para el aislamiento del patógeno, se colocan las muestras de hoja infectada en cámara húmeda a una temperatura de 18 a $20^{\circ} \mathrm{C}$, humedad relativa mayor del $90 \%$ y 18 horas de luz (Figura $\mathrm{N}^{\circ} 05$ ) hasta que se desarrolle el micelio presente en la muestra, para luego extraer parte del tejido infectado con mildiu y colocarlo sobre la superficie de una patata de variedad susceptible como Bintje, desinfectada, pelada y troceada, bajo las condiciones de temperatura, humedad y luz antes mencionados hasta que el patógeno desarrolle la mayor cantidad de micelio posible.
Posteriormente y en condiciones asépticas en la cámara de flujo laminar, se pasan pequeñas cantidades de micelio que se han desarrollado en la superficie de la patata para ser colocadas en un medio nutritivo solido de agar centeno para favorecer el crecimiento y desarrollo del patógeno.

El mantenimiento del aislado se realiza periódicamente cada dos a tres meses, en medio agar centeno (Figura $\mathrm{N}^{\circ} 06$ ). Los aislados mantenidos por más de un año deben ser rejuvenecidos para recuperar el poder de infección, esto se realiza pasando los aislados nuevamente por patata en cámaras húmedas, tal como se hizo en aislamiento del patógeno.

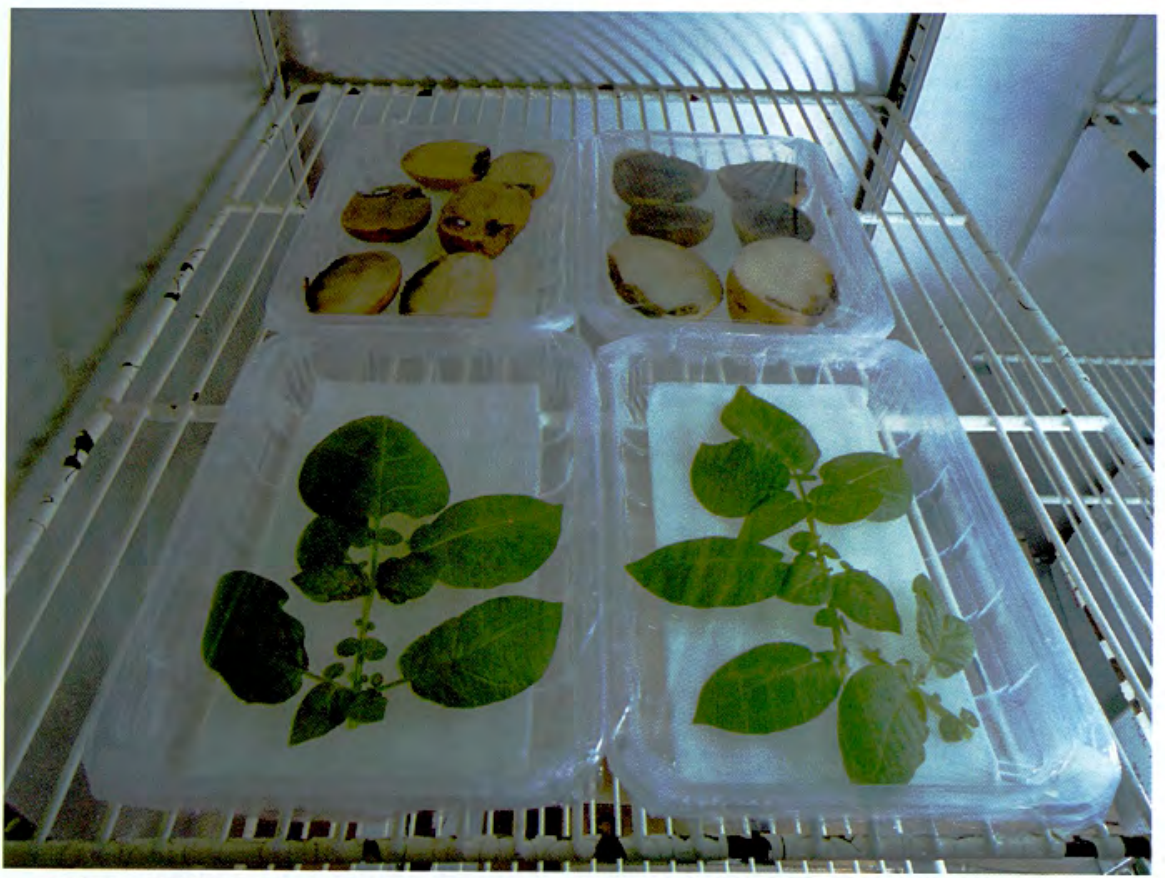

Figura $\mathrm{N}^{\circ} 05$. Muestras de hojas y tubérculos en cámara de crecimiento

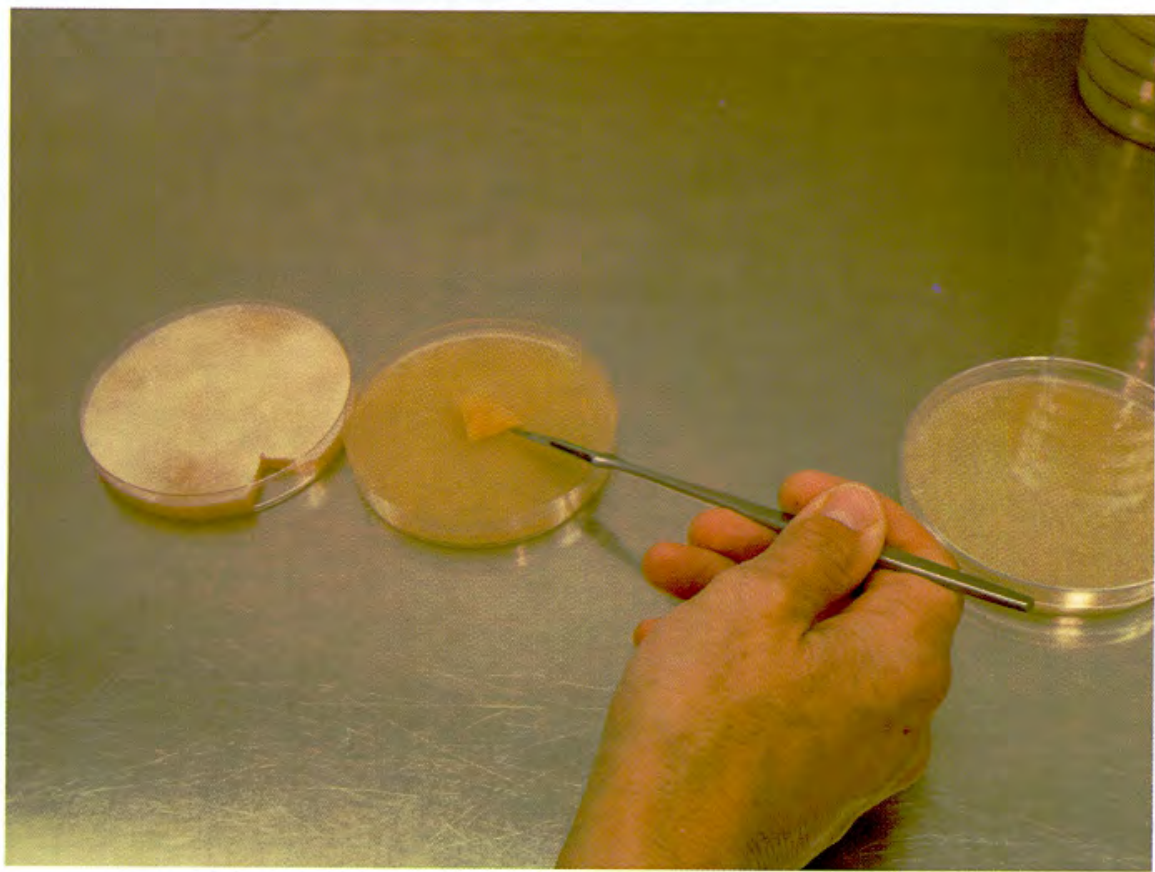

Figura $\mathrm{N}^{\circ} 06$. Mantenimiento del aislado en medio agar-centeno. 


\section{Determinación fenotípica del tipo de apareamiento (Fenotipado)}

Se realiza mediante cruzamiento in vitro de cepas de referencia del tipo sexual conocido $A 1$ o $A 2$ de $P$. infestans con los distintos aislados, en medio de cultivo Agar-centeno (Figura $\mathrm{N}^{\circ} 07$ ). Las placas se incuban durante 10-15 dias a $18^{\circ} \mathrm{C}$ y en total oscuridad. Transcurrido dicho periodo de tiempo, se lleva a cabo una observación de las placas mediante microscopía para determinar el tipo de apareamiento producido (reproducción sexual o asexual) a través de la identificación de las estructuras morfológicas características en cada caso (oosporas en la reproducción sexual o esporangios en el caso de la reproducción asexual). (ver Figura $\mathrm{N}^{\circ} 07$ )

De esta forma, aquellos que generan oosporas (espora sexual) con la cepa conocida del tipo $A 2$ son consideradas aislados del tipo de apareamiento $A 1$, en cambio los aislados que generan oosporas con la cepa de referencia $A 1$, son del tipo de apareamiento $A 2$.

\section{Determinación molecular del tipo de apareamiento (Genotipado)}

La validación de los tipos de apareamiento se realiza mediante el genotipado de los aislados por marcadores moleculares tipo CAPS (Cleaved Amplified
Polymorpbic Sequence).

El proceso se inicia con el lavado, con $4 \mathrm{ml}$ agua estéril y liofilización (deshidratación por sublimación) del micelio. Posteriormente se tritura el micelio liofilizado con nitrógeno líquido, y se realiza la extracción de $\mathrm{ADN}$ mediante kit comercial (DNeasy® Plant Mini, Qiagen). Finalmente se comprueba su calidad mediante el espectrofotómetro Nanodrop 2000.

Este protocolo permite obtener ADN de alto grado de pureza del patógeno, para posteriormente realizar una amplificación mediante la técnica PCR (Polymerase Chain Reaction) utilizando como cebadores W16-1 y W16-2, y una digestión con la endonucleasa de restricción HaeIII. Por último se realiza una electroforesis en gel de agarosa $(1 \%)$ y se visualiza mediante fluorescencia en Chemidocx XRS. El fin de esta técnica en este caso es la determinación de la presencia o ausencia de fragmentos específicos (locus) del genoma, característicos de los individuos en función a su tipo de apareamiento, $A 1 \mathrm{o} A 2$ (Figura $\left.\mathrm{N}^{\circ} 08\right)$.

El tipo de apareamiento $A 1$ muestra tres bandas patrón con un tamaño molecular de 600,550 y 50 pb, mientras que para el tipo de apareamiento $A 2$ presenta dos fragmentos de restricción con bandas de tamaño molecular de 550 y 50 pb. (Ver Figura $\mathrm{N}^{\circ} 08$ )

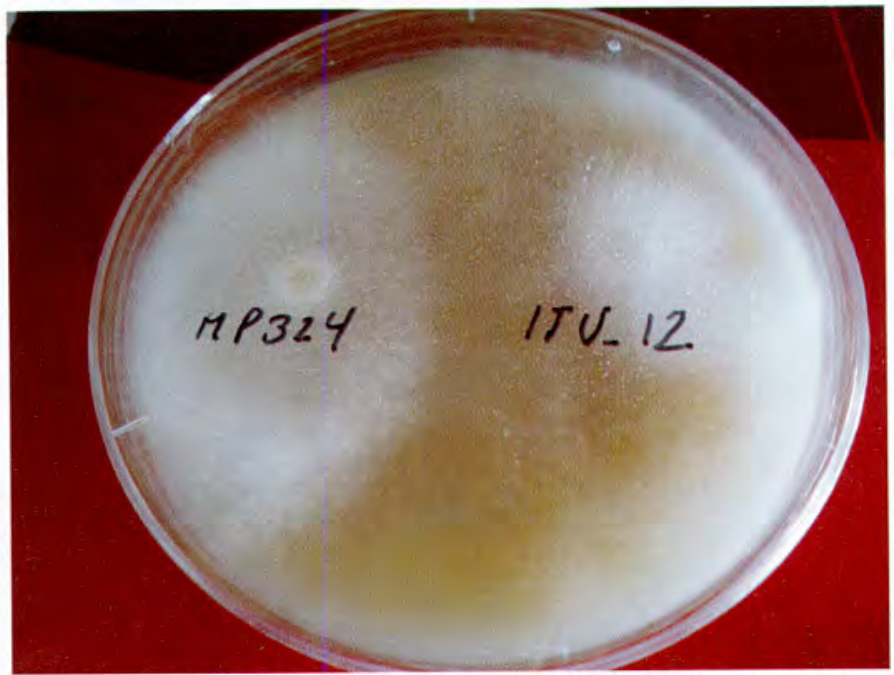

Figura $N^{\circ} 07$. Apareamiento de la cepa de referencia MP324 (A1) con un aislado sin identificar.

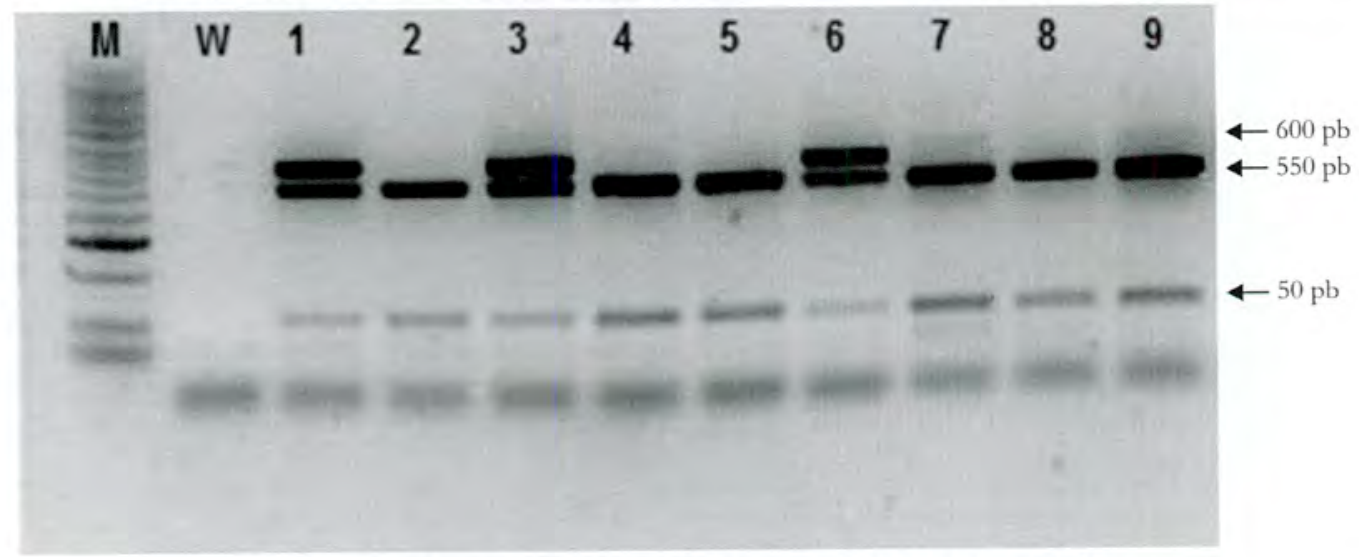

Figura 8. Fragmentos obtenidos mediante la técnica CAPS.

M: Marcador de peso molecular. W: Control interno (agua). Muestras del1 al 9: Cepas $A 1$ y $A 2$ de P. infestans tras la digestión. 


\section{Importancia de las condiciones meteorológicas}

Inicialmente, el patógeno requiere para su desarrollo temperaturas por encima de $10{ }^{\circ} \mathrm{C}$ y humedad superior del $90 \%$. Temperaturas superiores a $27-30{ }^{\circ} \mathrm{C}$ suelen detener su desarrollo. Estos requerimientos han hecho posible el desarrollo de modelos que permiten predecir, a partir de la recogida de datos meteorológicos, los periodos aptos para el desarrollo de la enfermedad. Las lesiones visibles aparecen sobre la planta al quinto día desde que se ha producido el ataque. Es por ello que, conociendo los datos de humedad y temperatura, podemos predecir el momento en que la enfermedad puede aparecer y determinar el momento óptimo para tratar. Para ello, tenemos sistemas sencillos como los periodos Smith o programas informáticos más sofisticados llamados DSSs (Decision Support Systems). Los datos obtenidos a partir del estudio de las poblaciones del patógeno ayudan a hacer reajustes en estos sistemas de predicción.

\section{Control}

El mildiu es la enfermedad que más pérdidas causa a nivel mundial. Se están haciendo grandes esfuerzos por monitorizar los cambios en su población y adaptar las estrategias de lucha año tras año.

Evitar la introducción del mildiu en las parcelas de cultivo mediante la rotación amplia de cultivos, eliminar tubérculos contaminados en los campos o sus alrededores, una adecuada densidad del cultivo y un buen manejo de riegos son prácticas culturales deseables.

La tendencia actual es realizar un control integrado de la enfermedad mediante la combinación de sistemas de predicción de la enfermedad con el uso de fungicidas que eviten su aparición o minimicen los daños. El uso combinado de fungicidas con diferente modo de acción previene la aparición de resistencias debidas al uso del mismo fungicida repetidamente. En la actualidad el mercado ofrece productos de contacto, translaminares y sistémicos para dar respuesta a las diferentes etapas del cultivo. En http://www.euroblight.net se puede encontrar información actualizada de las materias activas disponibles en el mercado junto con sus características.

\section{AGRADECIMIENTOS}

Este trabajo ha sido financiado por el INIA (RTA2011-00018-C03-01) y el Gobierno Vasco.

\section{REFERENCIAS BIBLIOGRÁFICAS}

Dowley L.J. 1995. Phytophthora infestans. Ed. European Association for Potato Research (EAPR). Proceedings of Workshop on the European network for development of an integrated control strategy of potato late blight. 1996-2013. http://www.euroblight.net .

\section{Correspondencia:}

Néstor Alor: nalor@neiker.net
Fecha de Recepción: 01/07/2014

Fecha de Aceptación: 09/07/2014 